Article

\title{
Carbon Deposition Behavior of Ni Catalyst Prepared by Combustion Method in Slurry Methanation Reaction
}

\author{
Keming $\mathrm{Ji}^{1,2}$, Fanhui Meng ${ }^{2, *}$, Jiayao Xun ${ }^{1}$, Ping Liu ${ }^{1}$, Kan Zhang ${ }^{1, *}, \mathrm{Zhong}{ }^{2}{ }^{2}$ \\ and Junhua Gao ${ }^{1}$ \\ 1 State Key Laboratory of Coal Conversion, Institute of Coal Chemistry, Chinese Academy of Sciences, \\ 27 South Taoyuan Road, Taiyuan 030001, China \\ 2 Key Laboratory of Coal Science and Technology of Ministry of Education and Shanxi Province, \\ Taiyuan University of Technology, Taiyuan 030024, China \\ * Correspondence: mengfanhui@tyut.edu.cn (F.M.); sxicc602@163.com (K.Z.); \\ Tel.: +8613935154736 (F.M.); +8618935139248 (K.Z.)
}

Received: 30 April 2019; Accepted: 25 June 2019; Published: 28 June 2019

\begin{abstract}
Ni} / \mathrm{Al}_{2} \mathrm{O}_{3}$ catalyst prepared by combustion method was applied in a slurry methanation reaction to study the catalytic performance, especially the regeneration performance. The catalyst properties were characterized by (X-Ray diffraction) XRD, Inductively coupled plasma atomic emission spectrometer (ICP-AES), Nitrogen adsorption-desorption, Transmission electron microscopy (TEM), Thermogravimetric analysis (TG/DTG), Temperature programmed oxidation (TPO), and $\mathrm{H}_{2}$ chemisorption before and after reaction. The results show that the catalyst deactivation was mainly due to carbon deposition, which exhibited amorphous carbon films and formed by the disproportionation of $\mathrm{CO}$. The carbon deposition was formed on the catalyst surface and existed as carbon films during the reaction, then it gradually separated from the catalyst surface, generated an overlapping multi-layer three-dimensional carbon structure, which covered the active site and blocked the pores. As a result, the metal surface area of catalyst decreases, as well as the activity. The carbon deposition could be removed by oxidative calcination without destroying the catalyst structure, the active sites could be re-exposed and the catalyst activity could be recovered.
\end{abstract}

Keywords: carbon deposition; catalyst deactivation; Ni catalyst; slurry-bed reactor; catalyst regeneration

\section{Introduction}

Coal is the most abundant fossil energy on Earth, which can be used to prepare coke [1], aromatics [2], methane [3-5], methanol [6], ammonia [7], gasoline [8] and other chemical products through coking, gasification and liquefaction. Among them, the process of coal gasification to methane has been extensively studied in recent years [9-11], due to its high energy conversion efficiency, short process flow and low equipment investment of unit product.

Syngas $\left(\mathrm{CO}+\mathrm{H}_{2}\right)$ methanation is the key technology for coal to methane, mostly using Ni-based catalyst. However, methanation is a strong exothermic reaction, $1 \%$ of the $\mathrm{CO}$ conversion could cause $74{ }^{\circ} \mathrm{C}$ adiabatic temperature rise [12]. The reactor bed is likely to overheat, leading to rapidly sintered catalyst. For a slurry-bed reactor with inert liquid medium, the heat reaction could be removed in time by the liquid paraffin wrapped catalyst, which could solve the problem of overheating in the bed. Hence, researchers have paid more attention to the slurry-bed methanation reaction process, the reaction temperature, pressure, velocity and other reaction process $[13,14]$. In addition, the structure and properties of the catalyst [15-18] have been systematically studied, and it was found that the preparation method can significantly affect the specific surface area, Ni particle size, dispersion and 
adsorption properties of the catalyst. Among them, the catalyst prepared by combustion method has a large specific surface area, small particle size and uniform dispersion of Ni. Furthermore, it has a large active metal surface area $[19,20]$. Under the conditions of $300{ }^{\circ} \mathrm{C}, 1.0 \mathrm{MPa}, 3000 \mathrm{~mL} \cdot \mathrm{g}^{-1} \cdot \mathrm{h}^{-1}$, the $\mathrm{CO}$ conversion and the $\mathrm{CH}_{4}$ selectivity reaches $94.3 \%$ and $93.7 \%$, respectively [21]. In our previous studies, combustion method has been applied in slurry phase methanation reaction, the influence of $\mathrm{Ni}$ contents [21]. precursor of supports [22], type of fuels [23] and other key influence factors on catalytic performances have been systematic researched.

Besides $\mathrm{CO}$ conversion and $\mathrm{CH}_{4}$ selectivity, stability is another key catalytic indicator. The primary reason for the stability and the deactivation of $\mathrm{Ni}$ catalyst is the carbon deposition of $\mathrm{Ni}$ [24]. At present, there are a large number of studies on the mechanism of carbon deposition [25], the structure of carbon deposition [26], the influence of carbon deposition on the activity of catalyst [27-30]. In the methanation reaction, the carbon deposition is mainly derived from the disproportionation of $\mathrm{CO}$ and decomposition of $\mathrm{CH}_{4}$. On the catalyst surface, the formation of a variety of morphologies of the amorphous carbon, part of the crystallization of carbon and graphite carbon, ultimately lead to $\mathrm{Ni}$ sintering, pore blockage, or active center covered, resulting in catalyst deactivation. The carbon deposition behavior of the catalyst is affected by a variety of factors such as reactor [31], temperature, pressure and other technological conditions [32], such as the structure and properties of the catalyst [33]. To our best knowledge, the catalyst regeneration and carbon deposition behavior for $\mathrm{CO}$ methanation in a slurry-bed reactor has not been reported.

In this study, $\mathrm{Ni} / \mathrm{Al}_{2} \mathrm{O}_{3}$ catalyst was prepared by combustion method. The catalytic stability and regeneration properties were investigated in a low-temperature slurry-bed reactor. Furthermore, the catalyst and its carbon deposition are characterized, as are the structure and properties of carbon deposition. The effects of carbon deposition on catalyst properties and catalytic performance are also discussed.

\section{Results}

\subsection{Catalytic Stability Evaluation in Slurry-bed}

The results of assessment of the $\mathrm{Ni} / \mathrm{Al}_{2} \mathrm{O}_{3}$ catalyst in the slurry-bed methanation system are shown in Figure 1. At the first $20 \mathrm{~h}$ of the reaction, the $\mathrm{CO}$ conversion and $\mathrm{CH}_{4}$ selectivity increase, up to $91.3 \%$ and $92.9 \%$, respectively. After a reaction time of $450 \mathrm{~h}$, the $\mathrm{CH}_{4}$ selectivity remains around $92 \%$, indicating that $\mathrm{CH}_{4}$ is the main product in the slurry-bed methanation reaction with a stable selectivity during the reaction. Meanwhile, the CO conversion decreases to $69.1 \%$ and the deactivation rate is $0.053 \% \mathrm{~h}^{-1}$. It was reported that the catalyst deactivation rate in the fixed-bed methanation system is $0.075 \% \mathrm{~h}^{-1}$ [34], $0.113 \% \mathrm{~h}^{-1}$ [35], $0.130 \% \mathrm{~h}^{-1}$ [36] and $0.360 \% \mathrm{~h}^{-1}$ [37]. Obviously, in the slurry-bed methanation system, the catalyst deactivation is slower and the stability is better than that of the fixed-bed system.

After the reaction, the catalyst was calcined in air atmosphere at $400{ }^{\circ} \mathrm{C}$ for $4 \mathrm{~h}$ to remove the carbon deposition, which may be present in the catalyst and then regenerated. The evaluation results of the catalyst after regeneration are shown in Figure 1b. The result shows that, in a reaction time of $100 \mathrm{~h}$, the average $\mathrm{CO}$ conversion and $\mathrm{CH}_{4}$ selectivity of refreshed catalyst reaches $89.6 \%$ and $91.8 \%$, respectively. Then, the CO conversion gradually decreases. After a reaction time of $250 \mathrm{~h}$, the $\mathrm{CO}$ conversion falls to $80.5 \%$, which is very closed to that of fresh catalyst, indicating that after the regeneration process, the catalyst performance is almost fully recovered. 

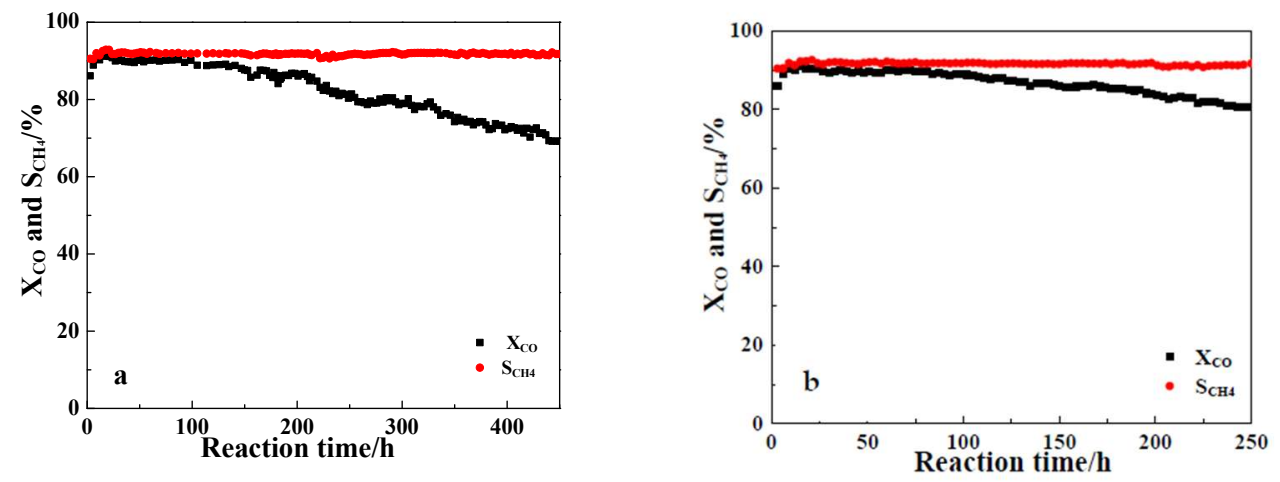

Figure 1. $\mathrm{CO}$ conversion and $\mathrm{CH}_{4}$ selectivity of fresh catalyst (a) and refreshed catalyst (b) in slurry-bed reactor.

\subsection{Catalyst Composition}

The XRD characterization of the catalyst is shown in Figure 2. The characteristic diffraction peaks of $\mathrm{Ni}$ and $\gamma-\mathrm{Al}_{2} \mathrm{O}_{3}$ can be observed in the fresh catalyst, indicating that the Ni phase is formed in the process of catalyst preparation and $\mathrm{Al}_{2} \mathrm{O}_{3}$ phase of the support is maintained. The diffraction peak of $\gamma-\mathrm{Al}_{2} \mathrm{O}_{3}$ is still presented in the catalyst, but the intensity of $\mathrm{Ni}$ is weaker than that of fresh catalyst, and gradually decreases with increasing reaction time. The diffraction peak of $\mathrm{Ni}$ is not observed in the catalyst after $450 \mathrm{~h}$. The decrease of Ni intensity indicates that the ordering of the Ni grains in the catalyst is deteriorated, which is related to the accumulation of carbon. The results show that the active carbon deposition firstly produced in the reaction can be dissolved in Ni particles, partially form carbonized nickel [26].

The XRD patterns of the catalyst after regeneration is also shown in Figure 2. It can be seen that the peak intensity of $\gamma-\mathrm{Al}_{2} \mathrm{O}_{3}$ and $\mathrm{Ni}$ in the catalyst after regeneration, is very close to that of the fresh catalyst.

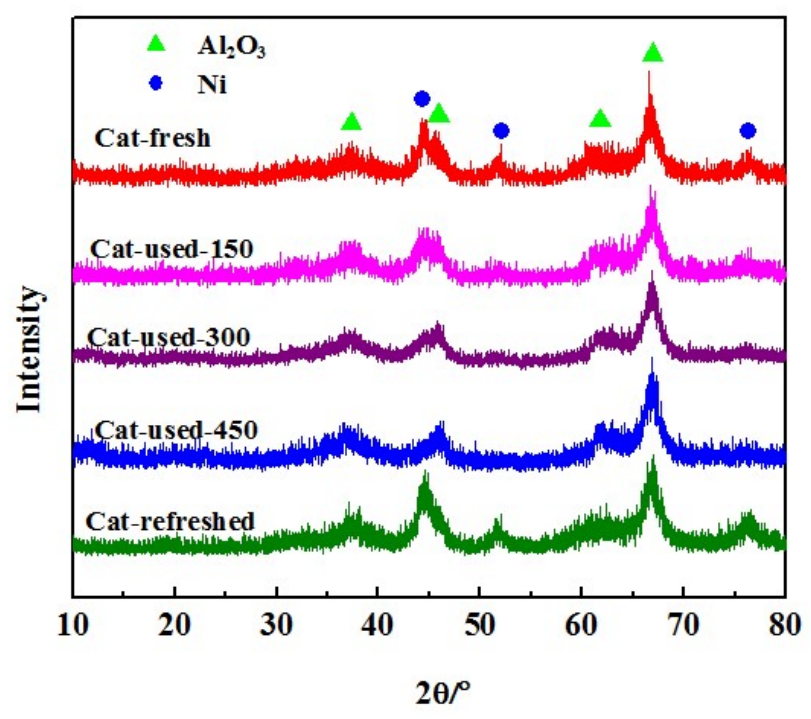

Figure 2. X-Ray diffraction patterns of catalysts.

The results of the Inductively coupled plasma atomic emission spectrometer characterization of the catalyst are shown in Table 1 . The theoretical Ni content of the catalyst is $20 \%$, the $\mathrm{Al}$ content is $42.4 \%$, and the mass ratio of $\mathrm{Ni} / \mathrm{Al}$ is 0.47 , the others is nonmetal element, $\mathrm{O}$. The $\mathrm{Ni}, \mathrm{Al}$ content and the mass ratio of Ni/Al of the fresh catalyst is $20.5 \%, 41.7 \%$, and 0.45 , respectively, in agreement with the theoretical value, indicating that the impregnated combustion of nickel-containing materials are all loaded in the catalyst. The contents of $\mathrm{Ni}$ and $\mathrm{Al}$ in the catalyst decrease to $19.0 \%$ and $39.7 \%$ 
respectively after $150 \mathrm{~h}$ reaction. After $450 \mathrm{~h}$, the contents of $\mathrm{Ni}$ and $\mathrm{Al}$ decrease to $15.4 \%$ and $32.9 \%$, respectively. It is concluded that as the reaction time is prolonged, the $\mathrm{Ni}$ and $\mathrm{Al}$ contents of the catalyst descend gradually, and nonmetal elements increase, which indicates indirectly that the amount of carbon deposition increases. The Ni/Al mass ratio of the catalyst after the reaction is still around 0.47 , which is not dramatically different from that of the fresh catalyst. The results indicate that there is no Ni component loss during the reaction.

Table 1. Inductively coupled plasma atomic emission spectrometer results of catalyst.

\begin{tabular}{cccc}
\hline Catalyst & $\begin{array}{c}\text { Ni Relative } \\
\text { Content/wt\% }\end{array}$ & $\begin{array}{c}\text { Al Relative } \\
\text { Content/wt \% }\end{array}$ & $\begin{array}{c}\text { Mass of } \\
\text { Ni/Al }\end{array}$ \\
\hline (Theoretical value) & 20 & 42.4 & 0.47 \\
Cat-fresh & 20.5 & 45.6 & 0.45 \\
Cat-used-150 & 19.0 & 39.7 & 0.48 \\
Cat-used-300 & 17.1 & 37.1 & 0.46 \\
Cat-used-450 & 15.4 & 32.9 & 0.47 \\
Cat-refreshed & 20.1 & 44.7 & 0.45 \\
\hline
\end{tabular}

\subsection{Microstructure and Morphology of Catalyst}

Table 2 shows the $\mathrm{N}_{2}$ adsorption characterization results of the catalyst. The specific surface area and average pore volume of fresh catalyst is $167 \mathrm{~m}^{2} \cdot \mathrm{g}^{-1}$ and $0.278 \mathrm{~cm}^{3} \cdot \mathrm{g}^{-1}$, respectively, and the average pore size is $7.1 \mathrm{~nm}$. The surface area of the catalyst changes a little after $150 \mathrm{~h}$, while the specific surface area decreases significantly to $128 \mathrm{~m}^{2} \cdot \mathrm{g}^{-1}$ after $300 \mathrm{~h}$, and the pore volume and pore size decrease observably, which indicates that the catalyst channels are blocked by carbon deposition. After $450 \mathrm{~h}$, the average pore size of the catalyst is reduced to $4.8 \mathrm{~nm}$, while the specific surface area and average pore volume increased to $134 \mathrm{~m}^{2} \cdot \mathrm{g}^{-1}$ and $0.219 \mathrm{~cm}^{3} \cdot \mathrm{g}^{-1}$. With increasing amount, carbon deposition from the surface of Ni particles adheres to the surface of the catalyst. The specific surface area, the average pore volume and pore size of the catalyst increased to $158 \mathrm{~m}^{2} \cdot \mathrm{g}^{-1}, 0.273 \mathrm{~cm}^{3} \cdot \mathrm{g}^{-1}$ and $6.8 \mathrm{~nm}$, respectively, in agreement with the fresh catalyst due to the removal of carbon deposition, and the blocked pore structure of the catalyst is recovered.

Table 2. Textural properties of catalysts.

\begin{tabular}{|c|c|c|c|}
\hline Catalyst & $\mathrm{S}_{\mathrm{BET}}\left(\mathrm{m}^{2} \cdot \mathrm{g}^{-1}\right)$ & $V_{p}\left(\mathrm{~cm}^{3} \cdot \mathrm{g}^{-1}\right)$ & $D_{p}(n m)$ \\
\hline Cat-fresh & 167 & 0.278 & 7.1 \\
\hline Cat-used-150 & 152 & 0.236 & 5.4 \\
\hline Cat-used-300 & 128 & 0.214 & 4.9 \\
\hline Cat-used-450 & 134 & 0.219 & 4.8 \\
\hline Cat-refreshed & 158 & 0.273 & 6.8 \\
\hline
\end{tabular}

The microstructure of the catalyst can be directly observed by TEM, which is helpful to understand the existence of carbon deposition. As shown in Figure 3, the fresh catalyst is in the form of granules with a diameter of 5-10 nm. Simultaneously, it has a uniform particle size and clear particles. After $150 \mathrm{~h}$ of methanation, the edge of the catalyst particles become blurred, indicating that a small amount of carbon is present on the catalyst surface [38]. When the reaction time increases to $300 \mathrm{~h}$, flat carbon film comes into being on the edge of the sample, wrapping in the catalyst surface. However, after $450 \mathrm{~h}$, the surface area of the catalyst continually increases, forming a multilayer carbon film, and the surface of the carbon film is no longer flat and superimposes on each other. After the regeneration process, the carbon species disappears, and the morphology of the catalyst is similar to that of fresh catalyst. 

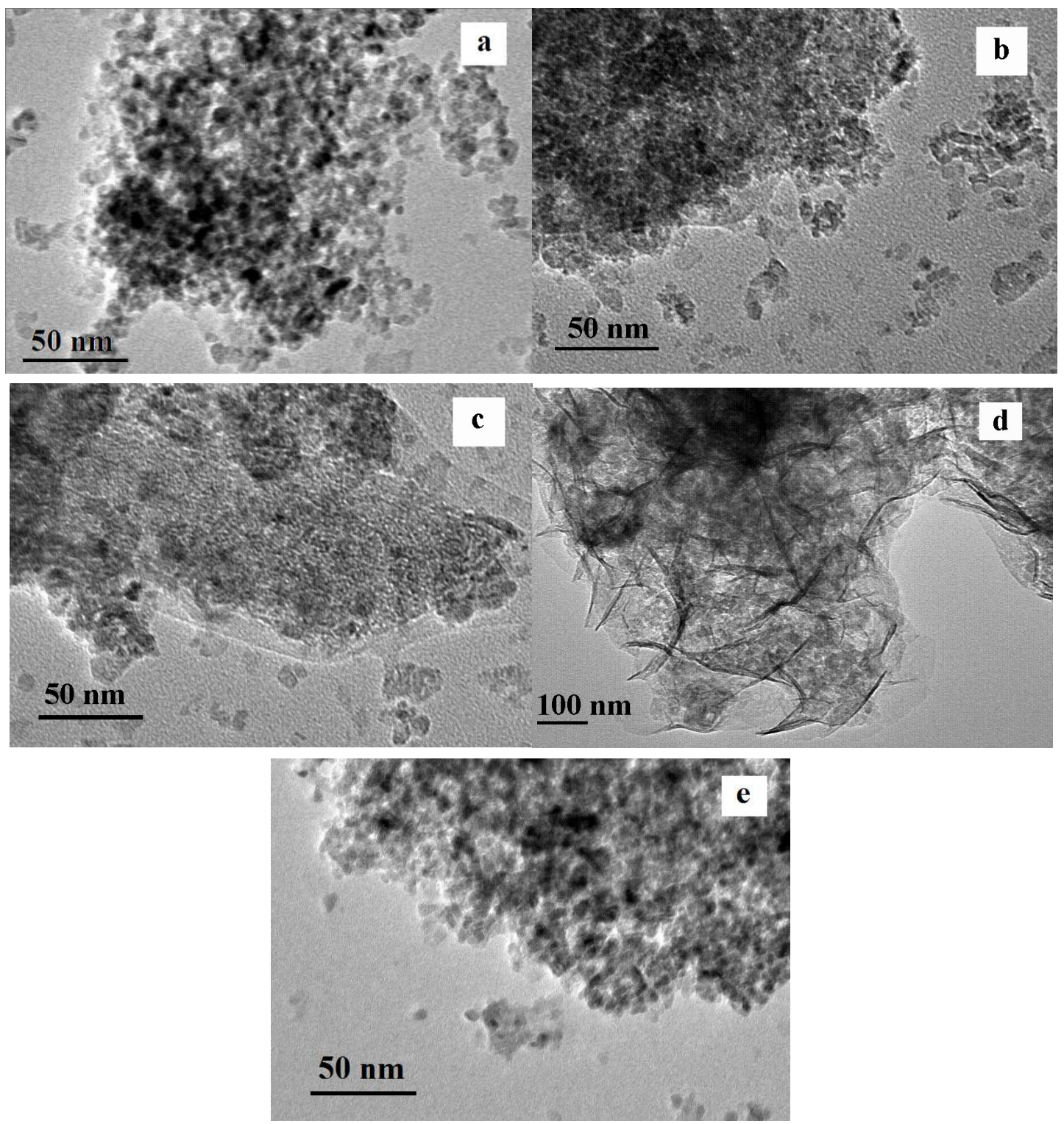

Figure 3. TEM of catalysts. (a) Cat-fresh, (b) Cat-used-150, (c) Cat-used-300, (d) Cat-used-450 and (e) Cat-refreshed.

\subsection{Carbon Deposition Analysis of Catalyst}

Previous studies have shown that the loss of weight in the Thermogravimetric analysis (TG) characterization of the catalyst after the methanation reaction is generally due to the oxidation of carbon deposition $[39,40]$. To obtain the carbon content of the catalyst, the $\mathrm{Ni} / \mathrm{Al}_{2} \mathrm{O}_{3}$ catalyst involved in the different stages of the methanation reaction was characterized by TG in the $\mathrm{CO}_{2}$ atmosphere. The results are shown in Figure 4. According to the figure, the fresh catalyst has almost no weight loss, that is, it does not decrease in quality caused by carbon deposition oxidation. The weight loss of the catalyst after the methanation reaction occurs above $280^{\circ} \mathrm{C}$, indicating that carbon deposition forms after the reaction. The carbon deposition capacity of the catalysts is $4.5 \%, 15.6 \%$ and $32.8 \%$ at $150 \mathrm{~h}, 300 \mathrm{~h}$ and $450 \mathrm{~h}$, respectively. It can be seen that as the reaction time is prolonged, the amount of carbon deposition increases. Nevertheless, the deactivated catalyst is oxidized and regenerated, it does not significantly lose weight, manifesting that the carbon deposition on the catalyst is substantially removed by the carbon deposition burning process. 


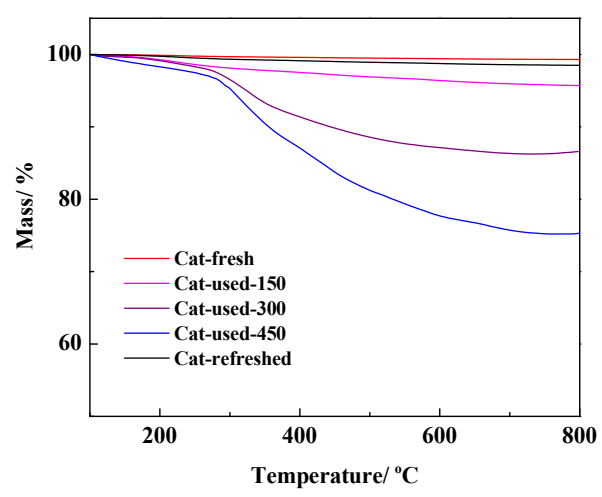

Figure 4. Thermogravimetric analysis of catalysts.

TPO is the programmed temperature oxidation, oxidation temperature of the carbon deposition can be obtained by it and the composition of carbon deposition can be deduced, the test results shown in Figure 5. It is observed that the catalyst has a significant oxidation peak at $230{ }^{\circ} \mathrm{C}$, corresponding to the oxidation of $\mathrm{Ni}$ [41]. The reacted catalyst has an oxidation peak at $360^{\circ} \mathrm{C}, 370{ }^{\circ} \mathrm{C}$ and $3800^{\circ} \mathrm{C}$, corresponding to the oxidation of carbon deposition. Previous studies have shown that carbon deposition is divided into amorphous carbon, partially crystallized carbon and graphite carbon according to the degree of crystallization, their oxidation temperature is above $250{ }^{\circ} \mathrm{C}-450{ }^{\circ} \mathrm{C}[42,43]$, $450{ }^{\circ} \mathrm{C}-550{ }^{\circ} \mathrm{C}$ [44] and $550^{\circ} \mathrm{C}$ [45], respectively. The temperature of the oxidation peaks shows that the carbon deposition on the catalyst is amorphous carbon. With the prolongation of methanation reaction time, the peak area of carbon deposition increases and the temperature of carbon deposition decreases. When the reaction time reaches $450 \mathrm{~h}$, the temperature of carbon deposition peak decreases to $360^{\circ} \mathrm{C}$, which indicates that the amount of carbon deposition increases in the reaction, the interaction between carbon deposition and catalyst becomes weaker, and oxidation is more likely to occur.

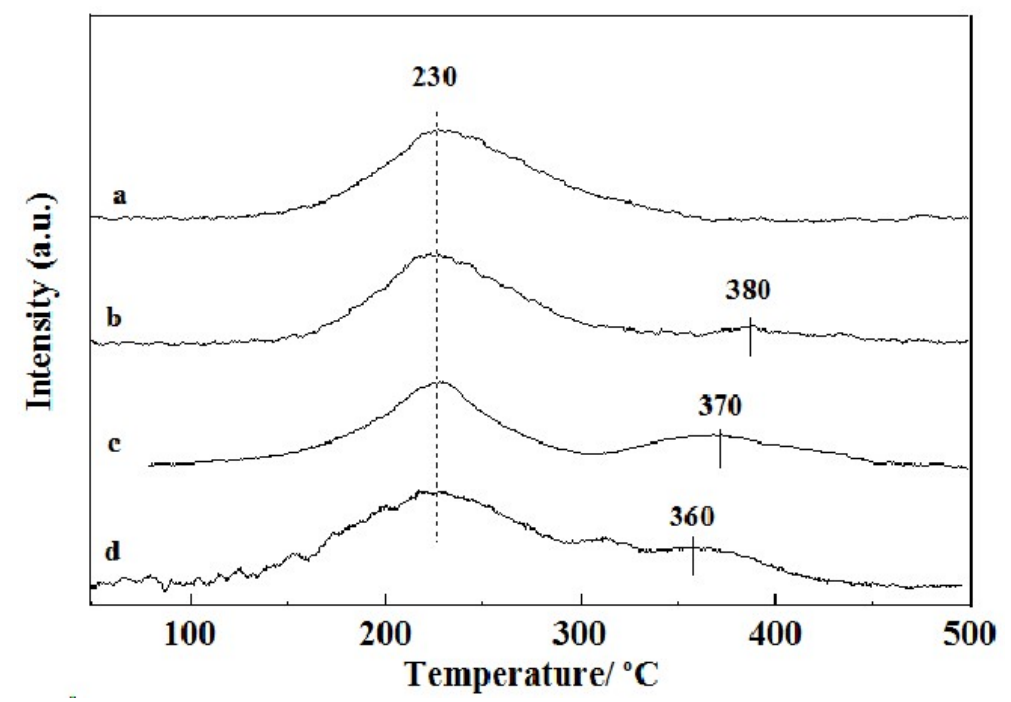

Figure 5. Temperature programmed oxidation of catalysts. (a) Cat-fresh, (b) Cat-used-150, (c) Cat-used-300 and (d) Cat-used-450.

\section{5. $\mathrm{H}_{2}$ Chemisorption Properties of Catalyst}

The $\mathrm{H}_{2}$ chemisorption results of the catalyst are shown in Table 3. It can be seen from the table that the surface area of the catalyst before reaction is $16.3 \mathrm{~m}^{2} \cdot \mathrm{g}^{-1}$ and the metal dispersion is $2.45 \%$. The surface area and metal dispersion of the catalysts were decreased after the reaction. After $450 \mathrm{~h}$, the two decrease to $9.0 \mathrm{~m}^{2} \cdot \mathrm{g}^{-1}$ and $1.35 \%$, respectively, because parts of the Ni particles are coated with the carbon film during the reaction, blocking some of the catalyst channels and reducing the $\mathrm{Ni}$ active 
sites exposed to the catalyst surface, metal surface area also decreases. The surface area and metal dispersion of the catalyst after the regeneration increase to $15.9 \mathrm{~m}^{2} \cdot \mathrm{g}^{-1}$ and $2.40 \%$, respectively, close to the fresh catalyst, which is due to the removal of the carbon deposition on the Ni surface during the regeneration process. The Ni phase can be re-exposed and subjected to $\mathrm{H}_{2}$ chemisorption.

Table 3. Metallic surface area and metal dispersion of catalysts.

\begin{tabular}{ccc}
\hline Catalyst & $\begin{array}{c}\text { Metallic Surface } \\
\text { Area } /\left(\mathbf{m}^{\mathbf{2}} \cdot \mathbf{g}_{\text {metal }} \mathbf{- 1}^{\mathbf{1}}\right)\end{array}$ & Metal Dispersion/\% \\
\hline Cat-fresh & 16.3 & 2.45 \\
Cat-used-150 & 15.3 & 2.29 \\
Cat-used-300 & 12.6 & 1.89 \\
Cat-used-450 & 9.0 & 1.35 \\
Cat-refreshed & 15.9 & 2.40 \\
\hline
\end{tabular}

\section{Discussion}

Based on the evaluation and characterization of the $\mathrm{Ni} / \mathrm{Al}_{2} \mathrm{O}_{3}$ catalyst prepared by the combustion method in the slurry-bed system, the causes of carbon deposition, the properties and morphology of carbon deposition, the relationship between the carbon deposition and the structure and activity of the catalyst were analyzed and discussed.

According to thermodynamics, in the methanation reaction and its reverse reaction, $\mathrm{CO}$ disproportionation and $\mathrm{CH}_{4}$ decomposition occurred mainly in the low-temperature range of $<650{ }^{\circ} \mathrm{C}$ and the high temperature range of $>600{ }^{\circ} \mathrm{C}$ [46], respectively. However, because of the limitation of the boiling point of the liquid paraffin, the temperature of the slurry-bed methanation was low, generally below $350^{\circ} \mathrm{C}\left(280^{\circ} \mathrm{C}\right.$ in this experiment). Therefore, the carbon deposition is mainly produced by the disproportionation of $\mathrm{CO}$ in the slurry-bed methanation reaction system. Research has shown that carbon deposition generated by CO disproportionation is mainly amorphous carbon [47], which is consistent with the results of experimental observations.

As the reaction time was prolonged, the amount of catalyst deposits increased and the methanation activity decreased.

At the initial stage of carbon deposition, the disproportion of $\mathrm{CO}$ occurred on the surface of $\mathrm{Ni}$ active, resulting in carbon active precursor $\mathrm{C}^{*}$. A small amount of $\mathrm{C}^{*}$ could be dissolved in the $\mathrm{Ni}$ to form $\mathrm{Ni}_{3} \mathrm{C}$ species. However, the doping of $\mathrm{Ni}_{3} \mathrm{C}$ caused the grain order of $\mathrm{Ni}$ to decrease. At this point $\mathrm{Ni}_{3} \mathrm{C}$ in the Ni particles were not saturated, the catalyst surface was without carbon deposition precipitation, and its activity did not show a significant decline.

With the further accumulation of carbon deposition, the carbon species dissolved in the $\mathrm{Ni}$ particles was saturated, it precipitated from the Ni grains, and transferred to the Ni grain boundary. It was reported that the accumulation of carbon deposition occurred mainly in the $\mathrm{Ni} /$ carrier interface and the outer surface of $\mathrm{Ni}$; the driving forces were the temperature gradient and the concentration gradient of carbon [41]. In the gas-liquid-solid three-phase reaction system of slurry-bed, there was a significant temperature gradient in the $\mathrm{Ni} /$ liquid interface due to the excellent heat transfer performance of the liquid phase; meanwhile, the weak polarity of liquid phase was similar to that of carbon, which corresponded to the like-dissolves-like effect. The combined action of temperature gradient and polarity matching led to the accumulation of precipitated carbon species in the $\mathrm{Ni} /$ liquid interface. Because of the low reaction temperature, carbon deposition did not form a relatively high degree of crystallinity of carbon species, such as carbon fiber, carbon tube, and even graphite carbon, but rather a less orderly film formed. The coating of the carbon film covered part of the Ni active site, blocking some of the catalyst channels, and hindering the gas phase mass transfer, finally causing the methanation activity to decrease.

When the carbon deposits continued to increase, the carbon film on the surface of the catalyst underwent deformation, crushing, stacking, and the morphology became broken and irregular. 
Furthermore, it was gradually separated from the catalyst surface to form a multilayer three-dimensional carbon structure. As the $\mathrm{Ni}$ active center was further covered, the catalyst pores were further blocked, and the surface area of the active metal decreased, leading to a decline of methanation activity. At the same time, the appearance and increase of the irregular carbon structure on the catalyst surface increased the catalyst surface area.

Since the carbon deposition in the slurry-bed methanation system generated in the $\mathrm{Ni} /$ liquid interface rather than the $\mathrm{Ni} /$ carrier interface, no Ni particles fell off and pore structure was not destroyed. The carbon deposition can be removed by oxidative roasting to re-expose the active site, thus the blocked pore structure and the catalyst activity are recovered.

\section{Experimental Section}

\subsection{Catalyst Preparation}

The catalyst was prepared by impregnation-combustion method. Firstly, $12.4 \mathrm{~g}$ of nickel nitrate ( $>98.0 \%$, Sinopharm Chemical Reagent, China) and $4.3 \mathrm{~g}$ of urea (A.R.; Tianjin Fengchuan Chemical Reagent, Tianjin, China) were dissolved in $10 \mathrm{~mL}$ distilled water. Then, $10 \mathrm{~g}$ of $\gamma-\mathrm{Al}_{2} \mathrm{O}_{3}$ (supplied by Zhengzhou Alumina Company, Zhengzhou, China) was slowly added into the solution and immersed for $24 \mathrm{~h}$. After the impregnation, the suspension was poured into a ceramic evaporator and placed in a muffle furnace for several minutes at a temperature of $300^{\circ} \mathrm{C}$. After it had spontaneously burned, a catalyst precursor was obtained. Then, it was grounded to $80-100$ mesh and reduced at $550{ }^{\circ} \mathrm{C}$ for $6 \mathrm{~h}$ with the gas $\mathrm{v}\left(\mathrm{H}_{2}\right) / \mathrm{v}\left(\mathrm{N}_{2}\right)=4 / 1$ at a flow rate of $125 \mathrm{~mL} / \mathrm{min}$, the as-received sample was methanation catalyst, designated as Cat-fresh. The loading content of Ni on catalyst was $20 \mathrm{wt} \%$.

\subsection{Catalyst Activity Evaluation and Regeneration}

$2 \mathrm{~g}$ of catalyst and $120 \mathrm{~mL}$ of liquid paraffin (A.R.; Tianjin Kemiou Chemical Reagent Co.; Ltd., Tianjin, China) were added to a $250 \mathrm{~mL}$ autoclave (CJF-0.25, Dalian Tongda Reactor Factory, Dalian, China), then $\mathrm{N}_{2}$ was introduced to sweep the air and enhance the pressure to $1.0 \mathrm{MPa}$, the feed gas was switched to $25 \% \mathrm{CO}-75 \% \mathrm{H}_{2}$. The activity test was performed under the conditions of $280{ }^{\circ} \mathrm{C}$, $1.0 \mathrm{MPa}$, and $3000 \mathrm{~mL} /(\mathrm{g} \cdot \mathrm{h})$ of space velocity. The off-gas was cooled by ethylene glycol at $1{ }^{\circ} \mathrm{C}$ to remove water vapor, then the gas was quantitatively analyzed on-line by a gas chromatography $(7980 \mathrm{~A}$, Agilent Technologies, Inc., Santa Clara, CA, USA), which was equipped with three valves and four columns, and measured by the wet gas flowmeter (LML-1, Jinzhiye Instrument Equipment Co. Ltd., Beijing, China). Helium was used as carrier gas. Flame Ionization Detector (FID) detector was used to analysis of $C_{1 \sim 4}$ hydrocarbons, equipped with HP-AL/S column $(30 \mathrm{~m} \times 530 \mu \mathrm{m} \times 15 \mu \mathrm{m})$; Thermal Conductivity Cell Detector (TCD) detector equipped with Porapak-Q column, HP-PLOT/Q column $(30 \mathrm{~m} \times 530 \mu \mathrm{m} \times 40 \mu \mathrm{m})$, and HP- MOLESIEVE column $(30 \mathrm{~m} \times 530 \mu \mathrm{m} \times 25 \mu \mathrm{m})$ was used to analyze $\mathrm{CO}_{2}$, and $\mathrm{CO}, \mathrm{CH}_{4}, \mathrm{~N}_{2}$.

By the end of the reaction, the catalyst was collected in the autoclave, and the liquid paraffin was removed from the surface of the catalyst by Soxhlet extractor, by using petroleum ether as solvent extraction. The extraction time was $200 \mathrm{~h}$. The extracted catalyst was dried to remove the petroleum ether, collected as cat-used-t, $t$ for the catalytic reaction time in units of $h$.

The catalyst after the reaction of $450 \mathrm{~h}$ was calcined at $400{ }^{\circ} \mathrm{C}$ for $4 \mathrm{~h}$ in air atmosphere to remove carbon deposition. It was then reduced in the same operation as the fresh catalyst, and designated as cat-refreshed. The regenerated catalyst was subjected to a slurry-bed methanation reaction under the same operating conditions as the fresh catalyst.

\subsection{Characterization}

X-ray diffraction (XRD) was used to characterize the catalyst by DX-2007 X-ray diffractometer (Haoyuan Instrument, Dandong, China), operating with $\mathrm{Cu} K_{\alpha}$ radiation of wavelength $\lambda=0.154056 \mathrm{~nm}$, Ni filter at $40 \mathrm{kV}$ and $30 \mathrm{~mA}$, the samples were scanned between $5^{\circ} \sim 85^{\circ}$ at a rate of $8^{\circ} / \mathrm{min}$. 
Inductively Coupled Plasma Atomic Emission Spectrometer (ICP-AES) was performed on an iCAP 6300 (Thermo Fisher Scientific, Waltham, MA, USA) for the test of Ni and Al content of catalyst sample.

Nitrogen adsorption-desorption isotherms were carried out by 3H-2000PS2 automatic device (Beishide Instrument, Beijing, China). The samples were degassed at $30 \mathrm{~Pa}$ and $130{ }^{\circ} \mathrm{C}$ for $1 \mathrm{~h}$. The $\mathrm{N}_{2}$ was adsorbed at liquid nitrogen temperature and the specific surface area was calculated using the BET formula.

Transmission electron microscopy (TEM) (JEOL, Tokyo, Japan) was carried out by JEM-2100F field emission electron microscopy operated at $200 \mathrm{kV}$. The samples were dispersed in ethanol for $10 \mathrm{~min}$, then the suspension was sprayed on a copper wire.

Thermogravimetric analysis (TG/DTG) was performed on STA409C (NETZSCH, Selb, Germany) integrated thermal analyzer at $\mathrm{CO}_{2}$ atmosphere. The test temperature range was $100 \sim 800{ }^{\circ} \mathrm{C}$, with the heating rate of $10^{\circ} \mathrm{C} / \mathrm{min}$.

Temperature programmed oxidation (TPO) was performed on Aurochem II 2920 automatic instrument (Micrometrics Inc., Londonderry, NH, USA). About $40 \mathrm{mg}$ catalysts were placed in a $\mathrm{U}$-shaped quartz reaction tube. The temperature raised to $350{ }^{\circ} \mathrm{C}$ at a rate of $10^{\circ} \mathrm{C} \cdot \mathrm{min}^{-1} \mathrm{using} \mathrm{He}$, kept blowing for $30 \mathrm{~min}$ at $350{ }^{\circ} \mathrm{C}$. Subsequently, until it had cooled down to $50{ }^{\circ} \mathrm{C}$, mixed gas of $\mathrm{V}\left(\mathrm{O}_{2}\right) / \mathrm{V}(\mathrm{He})=1 / 9$ was switched at the speed of $50 \mathrm{~mL} \cdot \mathrm{min}^{-1}$. After the baseline is stabilized, the temperature was raised to $700{ }^{\circ} \mathrm{C}$ at a rate of $10^{\circ} \mathrm{C} \cdot \mathrm{min}^{-1}$, and the TCD was used to detect the exhaust gas signal.

$\mathrm{H}_{2}$ chemisorption experiments were carried out with a Micrometrics Autochem II 2920 model multifunctional adsorption instrument (Micrometrics Inc, Londonderry, NH, USA). About $500 \mathrm{mg}$ samples were placed in a U-shaped quartz reaction tube, at the atmosphere of $\mathrm{V}\left(\mathrm{H}_{2}\right) / \mathrm{V}(\mathrm{Ar})=1 / 9$ and the flow rate of $50 \mathrm{~mL} \cdot \mathrm{min}^{-1}$, the temperature increased to $550{ }^{\circ} \mathrm{C}$ at the heating rate of $10^{\circ} \mathrm{C} \cdot \mathrm{min}^{-1}$ for $4 \mathrm{~h}$. When cooled down to $120^{\circ} \mathrm{C}$, blowing $1 \mathrm{~h}$ at atmosphere, then continued to cooled to $50^{\circ} \mathrm{C}$. When baseline was stable, 15 pulses were performed (every pulse adsorption for $3 \mathrm{~min}$ at the atmosphere of $\left.\mathrm{V}\left(\mathrm{H}_{2}\right) / \mathrm{V}(\mathrm{Ar})=1 / 9\right)$. The pulse adsorption signal was detected by TCD.

\section{Conclusion}

The carbon deposition of $\mathrm{Ni} / \mathrm{Al}_{2} \mathrm{O}_{3}$ catalyst, prepared by combustion method, was mainly due to the disproportionation of $\mathrm{CO}$, which existed as amorphous carbon. The regularity of carbon deposition and the activity of the catalyst were as follows: (1) Initial stage of carbon deposition: carbon species first dissolved in the Ni grains, but did not form a carbon crystal, and the catalyst pore structure and catalyst activity changed slightly. (2) Carbon dissolved in the Ni was saturated, then it began to precipitate. Under the influence of the temperature gradient and like-dissolves-like effect of the paraffin, the carbon deposition on the Ni surface formed into the carbon film, blocking the pores and reducing the surface area of the active metal. (3) The carbon increased and gradually dissociated from the surface of the catalyst. The morphology of the carbon film became broken and irregular, and finally the multilayer three-dimensional carbon structure was formed. The catalyst pores were further blocked, but the specific surface area increased due to the appearance and increase of the irregular carbon structure. Active metal surface area and activity both decreased.

Additionally, the carbon deposition only covered the active site of the catalyst, no Ni particles fell off and the pore structure was not destroyed. Therefore, the carbon deposition could be removed without damaging the catalyst structure by oxidative calcination, the catalyst active site was re-exposed and the catalyst activity was recovered.

Author Contributions: F.M., K.J. and Z.L. conceived and designed the experiments; K.J. performed the experiments; K.J. and J.X. analyzed the data; P.L., K.Z., Z.L. and J.G. contributed reagents/materials/analysis tools; K.J. and F.M. wrote the paper.

Acknowledgments: This work was supported by the Natural Science Foundation of Shanxi Province (201801D121056).

Conflicts of Interest: The authors declare no conflict of interest. 


\section{References}

1. Zhou, Q.; Liu, Q.; Shi, L.; Yan, Y.; Liu, Z. Behaviors of coking and radicals during reaction of volatiles generated from fixed-bed pyrolysis of a lignite and a subbituminous coal. Fuel Process. Technol. 2017, 161, 304-310. [CrossRef]

2. Zhang, S.; Xu, J.; Cai, Q.; Cui, Y. Production of aromatic hydrocarbons by hydrogenation-cocracking of bio-oil and methanol. Fuel Process. Technol. 2017, 161, 232-239. [CrossRef]

3. Cheng, C.; Shen, D.; Xiao, R.; Wu, C. Methanation of syngas $\left(\mathrm{H}_{2} / \mathrm{CO}\right)$ over the different Ni-based catalysts. Fuel 2017, 189, 419-427. [CrossRef]

4. Ren, J.; Li, H.; Jin, Y.; Zhu, J.; Liu, S.; Lin, J.; Li, Z. Silica/titania composite-supported Ni catalysts for CO methanation: effects of Ti species on the activity, anti-sintering, and anti-coking properties. Appl. Catal. B-Environ. 2017, 201, 561-572. [CrossRef]

5. Tao, M.; Xin, Z.; Meng, X.; Bian, Z.; Lv, Y. Highly dispersed nickel within mesochannels of SBA-15 for CO methanation with enhanced activity and excellent thermostability. Fuel 2017, 188, 267-276. [CrossRef]

6. Jeong, Y.; Kim, I.; Kang, J.Y.; Jeong, H.; Park, J.K.; Park, J.H.; Jung, J.C. Alcohol-assisted low temperature methanol synthesis from syngas over $\mathrm{Cu} / \mathrm{ZnO}$ catalysts: Effect of $\mathrm{pH}$ value in the co-precipitation step. J. Mol. Catal. A Chem. 2015, 400, 132-138. [CrossRef]

7. Zhang, C.; Chen, J.; Wen, Z. Assessment of policy alternatives and key technologies for energy conservation and water pollution reduction in China's synthetic ammonia industry. J. Cleaner Prod. 2012, 25, 96-105. [CrossRef]

8. Liu, G.; Larson, E.D. Comparison of coal/biomass co-processing systems with CCS for production of low-carbon synthetic fuels: Methanol-to-Gasoline and Fischer-Tropsch. Energy Procedia 2014, 63, 7315-7329. [CrossRef]

9. Yang, S.; Qian, Y.; Liu, Y.; Wang, Y.; Yang, S. Modeling, simulation, and techno-economic analysis of Lurgi gasification and BGL gasification for coal-to-SNG. Chem. Eng. Res. Des. 2017, 117, 355-368. [CrossRef]

10. Yang, S.; Liang, J.; Yang, S.; Qian, Y. A novel cascade refrigeration process using waste heat and its application to coal-to-SNG. Energy 2016, 115, 486-497. [CrossRef]

11. Li, S.; Ji, X.; Zhang, X.; Gao, L.; Jin, H. Coal to SNG: Technical progress, modeling and system optimization through exergy analysis. Appl. Energy 2014, 136, 98-109. [CrossRef]

12. Zhang, G.; Sun, T.; Peng, J.; Wang, S.; Wang, S. A comparison of Ni/SiC and Ni/Al2O3 catalyzed total methanation for production of synthetic natural gas. Appl. Catal. A-Gen. 2013, 462-463, 75-81. [CrossRef]

13. Kopyscinski, J.; Schildhauer, T.J.; Biollaz, S.M. Production of synthetic natural gas (SNG) from coal and dry biomass-A technology review from 1950 to 2009. Fuel 2010, 89, 1763-1783. [CrossRef]

14. Meng, F.; Li, X.; Li, M.; Cui, X.; Li, Z. Catalytic performance of $\mathrm{CO}$ methanation over La-promoted Ni/Al $\mathrm{Ol}_{3}$ catalyst in a slurry-bed reactor. Chem. Eng. J. 2017, 313, 1548-1555. [CrossRef]

15. Meng, F.; Li, X.; Shaw, G.; Smith, P.; Morgan, D.; Perdjon, M.; Li, Z. Sacrificial carbon strategy toward enhancement of slurry methanation activity and stability over $\mathrm{Ni}-\mathrm{Zr} / \mathrm{SiO}_{2}$ catalyst. Ind. Eng. Chem. Res. 2018, 57, 4798-4806. [CrossRef]

16. Meng, F.; Li, Z.; Liu, J.; Cui, X.; Zheng, H. Effect of promoter Ce on the structure and catalytic performance of $\mathrm{Ni} / \mathrm{Al}_{2} \mathrm{O}_{3}$ catalyst for $\mathrm{CO}$ methanation in slurry-bed reactor. J. Nat. Gas Sci. Eng. 2015, 23, $250-258$. [CrossRef]

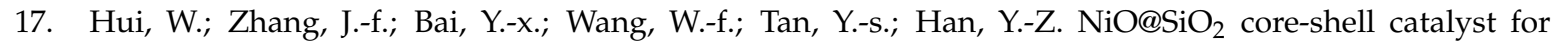
low-temperature methanation of syngas in slurry reactor. J. Fuel Chem. and Technol. 2016, 44, 548-556.

18. Zhang, J.; Bai, Y.; Zhang, Q.; Wang, X.; Zhang, T.; Tan, Y.; Han, Y. Low-temperature methanation of syngas in slurry phase over $\mathrm{Zr}$-doped $\mathrm{Ni} / \gamma-\mathrm{Al}_{2} \mathrm{O}_{3}$ catalysts prepared using different methods. Fuel 2014, 132, $211-218$. [CrossRef]

19. Gao, Y.; Meng, F.; Cheng, Y.; Li, Z. Influence of fuel additives in the urea-nitrates solution combustion synthesis of $\mathrm{Ni}_{-} \mathrm{Al}_{2} \mathrm{O}_{3}$ catalyst for slurry phase $\mathrm{CO}$ methanation. Appl. Catal. A-Gen. 2017, 534, 12-21. [CrossRef]

20. Gao, Y.; Meng, F.; Ji, K.; Song, Y.; Li, Z. Slurry phase methanation of carbon monoxide over nanosized $\mathrm{Ni}-\mathrm{Al}_{2} \mathrm{O}_{3}$ catalysts prepared by microwave-assisted solution combustion. Appl. Catal. A-Gen. 2016, 510, 74-83. [CrossRef] 
21. Ji, K.; Meng, F.; Li, Z. Ni-based catalysts prepared by impregnation combustion method for CO methanation in a slurry-bed reactor. Asia-Pac. J. Chem. Eng. 2016, 11, 151-157. [CrossRef]

22. Ke-Ming, J.; Fan-Hui, M.; Yuan, C.; Zhong, L. Solution combustion prepared Ni-based catalysts and their catalytic performance for slurry methanation. Chin. J. Inorg. Chem. 2015, 31, 267-274.

23. Keming, J.; Fanhui, M.; Yuan, G.; Zhong, L. Effect of fuel on structure and catalytic performance for slurry methanation over $\mathrm{Ni}-\mathrm{Al}_{2} \mathrm{O}_{3}$ catalysts prepared by combustion method. Chem. J. Chin. Univ. 2016, 37, 134-141.

24. Bartholomew, C.H. Mechanisms of catalyst deactivation. Appl. Catal. A-Gen. 2001, 212, 17-60. [CrossRef]

25. Han, X.; Yang, J.; Guo, H.; Qin, Z.; Zhao, S.; Lu, Y.; Li, Z.; Ren, J. Mechanism studies concerning carbon deposition effect of CO methanation on Ni-based catalyst through DFT and TPSR methods. Int. J. Hydrogen Energy 2016, 41, 8401-8411. [CrossRef]

26. Helveg, S.; López-Cartes, C.; Sehested, J.; Hansen, P.L.; Clausen, B.S.; Rostrup-Nielsen, J.R.; Abild-Pedersen, F.; Nørskov, J.K. Atomic-scale imaging of carbon nanofibre growth. Nature 2004, 427, 426-429. [CrossRef]

27. La Cava, A.I.; Bernardo, C.A.; Trimm, D.L. Studies of deactivation of metals by carbon deposition. Carbon 1982, 20, 219-223. [CrossRef]

28. Ruckenstein, E.; Wang, H.Y. Carbon deposition and catalytic deactivation during $\mathrm{CO}_{2}$ reforming of $\mathrm{CH}_{4}$ over $\mathrm{Co} / \gamma-\mathrm{Al}_{2} \mathrm{O}_{3}$ catalysts. J. Catal. 2002, 205, 289-293. [CrossRef]

29. Dabros, T.M.H.; Andersen, M.L.; Lindahl, S.B.; Hansen, T.W.; Høj, M.; Gabrielsen, J.; Grunwaldt, J.D.; Jensen, A.D. Hydrodeoxygenation (HDO) of aliphatic oxygenates and phenol over $\mathrm{NiMo} / \mathrm{MgAl}_{2} \mathrm{O}_{4}$ : reactivity, inhibition, and catalyst reactivation. Catalysts 2019, 9, 521. [CrossRef]

30. Gomes, R.; Costa, D.; Junior, R.; Santos, M.; Rodella, C.; Fréty, R.; Beretta, A.; Brandão, S. Dry reforming of methane over NiLa-based catalysts: influence of synthesis method and Ba addition on catalytic properties and stability. Catalysts 2019, 9, 313. [CrossRef]

31. Chen, L.; Hao, Z.; Yang, T.; Liu, W.; Zhang, D. Carbon deposition behavior of a Co-Ni aerogel catalyst in $\mathrm{CH}_{4}$ oxy- $\mathrm{CO}_{2}$ reforming using various types of reactors. Int. J. Hydrogen Energy 2014, 39, 15474-15481. [CrossRef]

32. Remiro, A.; Valle, B.; Aguayo, A.T.; Bilbao, J.; Gayubo, A.G. Operating conditions for attenuating $\mathrm{Ni} / \mathrm{La}_{2} \mathrm{O}_{3}-\alpha \mathrm{Al}_{2} \mathrm{O}_{3}$ catalyst deactivation in the steam reforming of bio-oil aqueous fraction. Fuel Process Technol. 2013, 115, 222-232. [CrossRef]

33. Li, Z.; Hu, X.; Zhang, L.; Liu, S.; Lu, G. Steam reforming of acetic acid over $\mathrm{Ni} / \mathrm{ZrO}_{2}$ catalysts: Effects of nickel loading and particle size on product distribution and coke formation. Appl. Catal. A-Gen. 2012, 417-418, 281-289. [CrossRef]

34. Li, J.; Zhou, L.; Li, P.; Zhu, Q.; Gao, J.; Gu, F.; Su, F. Enhanced fluidized bed methanation over a Ni/Al $2 \mathrm{O}_{3}$ catalyst for production of synthetic natural gas. Chem. Eng. J. 2013, 219, 183-189. [CrossRef]

35. Zhang, J.; Xin, Z.; Meng, X.; Tao, M. Activity and stability of nickel based MCM-41 methanation catalysts for production of synthetic natural gas. CIESC J. 2014, 65, 160-168.

36. Panagiotopoulou, P.; Kondarides, D.I.; Verykios, X.E. Selective methanation of CO over supported Ru catalysts. Appl. Catal. B-Environ. 2009, 88, 470-478. [CrossRef]

37. Zhao, A.; Ying, W.; Zhang, H.; Ma, H.; Fang, D. Ni- $\mathrm{Al}_{2} \mathrm{O}_{3}$ catalysts prepared by solution combustion method for syngas methanation. Catal. Commun. 2012, 17, 34-38. [CrossRef]

38. Chen, X.; Tadd, A.R.; Schwank, J.W. Carbon deposited on Ni/CeZrO isooctane autothermal reforming catalysts. J. Catal. 2007, 251, 374-387. [CrossRef]

39. Hu, D.; Gao, J.; Ping, Y.; Jia, L.; Gunawan, P.; Zhong, Z.; Xu, G.; Gu, F.; Su, F. Enhanced Investigation of CO Methanation over $\mathrm{Ni} / \mathrm{Al}_{2} \mathrm{O}_{3}$ Catalysts for Synthetic Natural Gas Production. Ind. Eng. Chem. Res. 2012, 51, 4875-4886. [CrossRef]

40. Guo, X.; Peng, Z.; Hu, M.; Zuo, C.; Traitangwong, A.; Meeyoo, V.; Li, C.; Zhang, S. Highly active Ni-based catalyst derived from double hydroxides precursor for low temperature $\mathrm{CO}_{2}$ methanation. Ind. Eng. Chem. Res. 2018, 57, 9102-9111. [CrossRef]

41. Struis, R.P.; Schildhauer, T.J.; Czekaj, I.; Janousch, M.; Biollaz, S.M.; Ludwig, C. Sulphur poisoning of Ni catalysts in the SNG production from biomass: A TPO/XPS/XAS study. Appl. Catal. A-Gen. 2009, 362, 121-128. [CrossRef]

42. Le Valant, A.; Bion, N.; Can, F.; Duprez, D.; Epron, F. Preparation and characterization of bimetallic $\mathrm{Rh}-\mathrm{Ni} / \mathrm{Y}_{2} \mathrm{O}_{3}-\mathrm{Al}_{2} \mathrm{O}_{3}$ for hydrogen production by raw bioethanol steam reforming: influence of the addition of nickel on the catalyst performances and stability. Appl. Catal. B-Environ. 2010, 97, 72-81. [CrossRef] 
43. Therdthianwong, S.; Srisiriwat, N.; Therdthianwong, A.; Croiset, E. Reforming of bioethanol over $\mathrm{Ni}_{2} / \mathrm{Al}_{2} \mathrm{O}_{3}$ and $\mathrm{Ni} / \mathrm{CeZrO}{ }_{2} / \mathrm{Al}_{2} \mathrm{O}_{3}$ catalysts in supercritical water for hydrogen production. Int. J. Hydrogen Energy 2011, 36, 2877-2886. [CrossRef]

44. Lu, Y.; Li, S.; Guo, L.; Zhang, X. Hydrogen production by biomass gasification in supercritical water over $\mathrm{Ni} / \gamma \mathrm{Al}_{2} \mathrm{O}_{3}$ and $\mathrm{Ni} / \mathrm{CeO}_{2}-\gamma \mathrm{Al}_{2} \mathrm{O}_{3}$ catalysts. Int. J. Hydrogen Energy 2010, 35, 7161-7168. [CrossRef]

45. Zhang, L.; Li, W.; Liu, J.; Guo, C.; Wang, Y.; Zhang, J. Ethanol steam reforming reactions over $\mathrm{Al}_{2} \mathrm{O}_{3} \cdot \mathrm{SiO}_{2}$-supported Ni-La catalysts. Fuel 2009, 88, 511-518. [CrossRef]

46. Gao, J.; Wang, Y.; Ping, Y.; Hu, D.; Xu, G.; Gu, F.; Su, F. A thermodynamic analysis of methanation reactions of carbon oxides for the production of synthetic natural gas. RSC Adv. 2012, 2, 2358-2368. [CrossRef]

47. Bartholomew, C.H. Carbon deposition in steam reforming and methanation. Catal. Rev. 1982, $24,67-112$. [CrossRef]

(C) 2019 by the authors. Licensee MDPI, Basel, Switzerland. This article is an open access article distributed under the terms and conditions of the Creative Commons Attribution (CC BY) license (http://creativecommons.org/licenses/by/4.0/). 